\title{
Fitness implications of sex-specific catch-up growth in Nephila senegalensis, a spider with extreme reversed SSD
}

\author{
Rainer Neumann ${ }^{\text {Corresp.., }}{ }^{1}$, Nicole Ruppel ${ }^{1}$, Jutta M. Schneider ${ }^{1}$ \\ ${ }^{1}$ Zoologisches Institut, Biozentrum Grindel, Universität Hamburg, Hamburg, Germany \\ Corresponding Author: Rainer Neumann \\ Email address: epeira@web.de
}

Background. Animal growth is often constrained by unfavourable conditions and divergences from optimal body size can be detrimental to an individual's fitness, particularly in species with determinate growth and a narrow time-frame for life-time reproduction. Growth restriction in early juvenile stages can later be compensated by means of plastic developmental responses, such as adaptive catch-up growth (the compensation of growth deficits through delayed development). Although sex differences regarding the mode and degree of growth compensation have been coherently predicted from sex-specific fitness payoffs, inconsistent results imply a need for further research. We used the African Nephila senegalensis, representing an extreme case of female-biased SSD, to study fitness implications of sex-specific growth compensation. We predicted effective catch-up growth in early food-restricted females to result in full compensation of growth deficits and a life-time fecundity (LTF) equivalent to unrestricted females. Based on a stronger trade-off between size-related benefits and costs of a delayed maturation, we expected less effective catch-up growth in males.

Methods. We tracked the development of over one thousand spiders in different feeding treatments, e.g. comprising a fixed period of early low feeding conditions followed by unrestricted feeding conditions, permanent unrestricted feeding conditions, or permanent low feeding conditions as a control. In a second experimental section, we assessed female fitness by measuring LTF in a subset of females. In addition, we tested whether compensatory development affected the reproductive lifespan in both sexes and analysed genotype-by-treatment interactions as a potential cause of variation in life-history traits.

Results. Both sexes delayed maturation to counteract early growth restriction, but only females achieved full compensation of adult body size. Female catch-up growth resulted in equivalent LTF compared to unrestricted females. We found significant interactions between experimental treatments and sex as well as between treatments and family lineage, suggesting that family-specific responses contribute to the unusually large variation of life-history traits in Nephila spiders. Our feeding treatments had no effect on the reproductive lifespan in either sex.

Discussion. Our findings are in line with predictions of life-history theory and corroborate strong fecundity selection to result in full female growth compensation. Males showed incomplete growth compensation despite a delayed development, indicating relaxed selection on large size and a stronger trade-off between late maturation and size-related benefits. We suggest that moderate catch-up growth in males is still adaptive as a 'bet-hedging' strategy to disperse unavoidable costs between life-history traits affected by early growth restriction (the duration of development and adult size). 
Fitness implications of sex-specific catch-up growth in Nephila senegalensis, a spider with extreme reversed SSD

Rainer Neumann, Nicole Ruppel, and Jutta M. Schneider

Zoologisches Institut, Biozentrum Grindel, Universität Hamburg, Martin-Luther-King-Platz 3, 20146 Hamburg, Germany

JMS and RN dedicate this work to the memory of our late colleague Nicole Ruppel (3.10.1978-24.2.2016)

Correspondence:

Rainer Neumann (corresponding author)

E-mail: epeira@web.de

Phone: (049)4042838 7894

Jutta M. Schneider

E-Mail: jutta.schneider@uni-hamburg.de

Phone: (049)4042838 3878 


\section{Abstract}

2

3 Background. Animal growth is often constrained by unfavourable conditions and divergences

4 from optimal body size can be detrimental to an individual's fitness, particularly in species with

5 determinate growth and a narrow time-frame for life-time reproduction. Growth restriction in

6 early juvenile stages can later be compensated by means of plastic developmental responses,

7 such as adaptive catch-up growth (the compensation of growth deficits through delayed

8 development). Although sex differences regarding the mode and degree of growth compensation have been coherently predicted from sex-specific fitness payoffs, inconsistent results imply a need for further research. We used the African Nephila senegalensis, representing an extreme case of female-biased SSD, to study fitness implications of sex-specific growth compensation. We predicted effective catch-up growth in early food-restricted females to result in full compensation of growth deficits and a life-time fecundity (LTF) equivalent to unrestricted females. Based on a stronger trade-off between size-related benefits and costs of a delayed maturation, we expected less effective catch-up growth in males.

Methods. We tracked the development of over one thousand spiders in different feeding treatments, e.g. comprising a fixed period of early low feeding conditions followed by unrestricted feeding conditions, permanent unrestricted feeding conditions, or permanent low feeding conditions as a control. In a second experimental section, we assessed female fitness by measuring LTF in a subset of females. In addition, we tested whether compensatory development affected the reproductive lifespan in both sexes and analysed genotype-bytreatment interactions as a potential cause of variation in life-history traits.

Results. Both sexes delayed maturation to counteract early growth restriction, but only females achieved full compensation of adult body size. Female catch-up growth resulted in equivalent LTF compared to unrestricted females. We found significant interactions between experimental treatments and sex as well as between treatments and family lineage, suggesting that family- 
27 specific responses contribute to the unusually large variation of life-history traits in Nephila spiders. Our feeding treatments had no effect on the reproductive lifespan in either sex.

Discussion. Our findings are in line with predictions of life-history theory and corroborate strong fecundity selection to result in full female growth compensation. Males showed incomplete growth compensation despite a delayed development, indicating relaxed selection on large size and a stronger trade-off between late maturation and size-related benefits. We suggest that moderate catch-up growth in males is still adaptive as a 'bet-hedging' strategy to disperse unavoidable costs between life-history traits affected by early growth restriction (the duration of development and adult size).

\section{Introduction}

Body size and the duration of development are among the most fitness-relevant life-history traits and have been extensively studied in various animal taxa (reviewed in Blanckenhorn 2005; Nylin \& Gotthard 1998; Roff 2002). Generally constrained by a trade-off between a favourable size at the onset of reproduction and the time necessary to reach it (Blanckenhorn 2000; Roff 1992), animal growth depends on both inherited growth trajectories and plastic modifications of them (Chase 1999; Dmitriew 2011). Extrinsic factors that may influence the mode of development include parasite infestations and other pathogens (Paez et al. 2015; Vergauwen et al. 2011), cues of present or future environmental conditions (Kasumovic \& Brooks 2011), ambient temperature (Kingsolver et al. 2004), and food supply (Stearns 1992; Wilson \& Osbourn 1960).

Growth strategies and optimal body size may differ markedly between the sexes, which is particularly evident in sexually size-dimorphic species (Blanckenhorn 2005). As large males tend to succeed in male-male competition across animal taxa, body size in males is often subject to sexual selection, resulting in male-biased sexual size dimorphism (SSD) (Kingsolver \& Pfennig 2004). Still enigmatic conditions are found in species with female-biased SSD, which mainly occurs in oviparous animals, like fishes (Barreto et al. 2003), amphibians (Hector et al. 2012; Nali et al. 2014), and many invertebrates (Honek 1993; Smith \& Brockmann 2014) including 
56 spiders (Cheng \& Kuntner 2015; Foellmer \& Moya-Laraño 2007; Higgins et al. 2011; Schneider \& 57 Andrade 2011). As females are strongly selected to produce large numbers of eggs, increased 58 female size through fecundity selection is generally well supported in these species (Blanckenhorn 2005; Nylin \& Gotthard 1998). Males, however, apparently are selected to stay small, which has been related to improved mobility and agility during mate search (MoyaLaraño et al. 2002; Moya-Laraño et al. 2009), a decreased risk of predation and female sexual cannibalism (Foellmer \& Fairbairn 2004), benefits of protandry through rapid maturation (Blanckenhorn et al. 2007), and reduced energy expenditures (Blanckenhorn 2000; Blanckenhorn 2005).

Optimization of development and growth may be difficult in non-constant environments. Basic strategies that permit fitness maximization under invariant conditions may need to be refined in response to environmental changes (Foster \& Kreitzman 2009). While alterations of environmental conditions often appear as recurring sequences, irregular fluctuations of environmental parameters are also common in a range of habitats. Such unpredictable conditions pose a threat to an individual's fitness, particularly in species in which reproductive success depends on a single reproductive period (Abrams et al. 1996). For example, unfavourable temperatures or food restriction may result in a delay of development, which can increase juvenile predation risk, but also lower reproductive prospects in individuals that reach maturity too late (end-of-season penalty; e.g. De Block et al. 2008; Higgins 2000).

Phenotypic plasticity (the capacity of a genotype to express different phenotypes in different environments; West-Eberhard 2003) provides the potential to counteract a period of unfavourable growth conditions in juvenile stages by means of adaptive developmental responses, e.g. compensatory growth and catch-up growth (Dmitriew 2011; Krause \& Caspers 2016; Metcalfe \& Monaghan 2001; Walzer et al. 2015). Compensatory growth refers to elevated growth under improved conditions, whereby a delay of sexual maturation is minimized. In contrast, adaptive catch-up growth is defined as a strategy to reach a favourable adult size at the expense of delaying maturation (Hector \& Nakagawa 2012; Livingston et al. 2014). Compensatory developmental mechanisms enable animals to either limit or entirely prevent fitness costs that would follow from a period of adverse growth conditions without the 
85

86

87

88

89

90

91

92

93

94

95

96

97

98

capacity for such flexible responses. However, early food restriction and subsequent growth compensation may entail intrinsic costs that can even lead to a reduction in lifespan (English \& Uller 2016; Hornick et al. 2000; Reichert et al. 2015).

As benefits and costs of developmental compensation may differ considerably between males and females, integrating pre-estimated divergent selection on body size may substantiate experimental work on such strategies. Plastic modifications of life-history traits have been related to experimental feeding regimes in a range of studies (Bauerfeind \& Fischer 2005; Bonneaud et al. 2016; Dahl et al. 2012; Davidowitz et al. 2003; Fernandez-Montraveta \& MoyaLarano 2007; Kleinteich \& Schneider 2011; Krause \& Caspers 2016), but relatively few of these have addressed sex-specific differences regarding compensatory development (Arnold et al. 2007; Chin et al. 2013; Tawes \& Kelly 2017).

In general, predictions concerning such differences are based on (1) proposed sex-specific net benefits of growth compensation (i.e. the sex whose fitness depends stronger on large body size is expected to show a higher degree of growth compensation), (2) on the possibility to increase size after sexual maturation (i.e. determinate versus indeterminate growth; with determinate growth generating stronger selection pressure to compensate growth deficits), and (3) on potential long-term costs of compensatory development (Livingston et al. 2014). Previous studies, however, are inconsistent as to whether predictions were met or not (Barreto et al. 2003; Livingston et al. 2014; Stillwell \& Davidowitz 2010; Tawes \& Kelly 2017), thus indicating that possible trade-offs between growth compensation, taxon-dependent lifehistory, and environmental conditions that determine the adaptive value of compensation require further research.

Species showing strong SSD are particularly suitable model systems to investigate sex-specific compensatory mechanisms, because especially pronounced sex-differences concerning size selection can be comparatively studied in a single species. Golden-silk spiders (genus Nephila, family Araneidae) show some of the most extreme cases of female-biased SSD (Kuntner et al. 2013). Male and female size in these spiders has been suggested to have evolved independently, with steady fecundity-driven selection on increased female size, whereas phylogenetic analyses did not reveal a consistent evolutionary trend towards male size- 
114 reduction (Higgins et al. 2011; Kuntner \& Elgar 2014). In addition, several studies have reported 115 large male advantages in the context of mating (Christenson \& Goist 1979; Elgar et al. 2003; 116 Elgar \& Fahey 1996; Rittschof 2010). Causes of small male size remain thus ambiguous, which 117 also applies to the remarkable within-sex size variation in many species (Elgar \& Fahey 1996; 118 Higgins et al. 2011; Schneider \& Elgar 2005). Nephila spiders are short-lived animals with determinate growth (Fromhage et al. 2007; Miyashita 2005; Rittschof 2011) and individuals of both sexes mature and reproduce within a limited time frame and within their own cohort (Higgins 2000; Higgins et al. 2011).

Natural populations exposed to different environmental conditions have been studied in the American N. clavipes (Higgins 1993; Higgins 1992). This species is bivoltine in some populations, where first-generation females mature at larger average size than second-generation females. However, first-generation females pass through early development in the dry season, experiencing low feeding success and hence unfavourable juvenile growth conditions. These females may have adaptively delayed maturation, later taking advantage of improving feeding conditions to eventually mature at large size (Higgins 1992). While these observations hint towards catch-up growth in females, experimental work is needed to test predictions following from this mechanism; specifically in comparison with permanently food-restricted and permanently well-fed individuals. Furthermore, the inclusion of males is essential to access sexspecific differences in an integral procedure to understand selection in this system.

Here, we consider the above-mentioned observations in the light of current research focussing on plastic compensatory mechanisms in sexually size-dimorphic species (Chin et al. 2013; Kahn et al. 2012; Livingston et al. 2014). Using the African N. senegalensis, we implemented a comprehensive approach consisting of two successive experimental sections. In the first section, we manipulated the study animals' feeding conditions, rearing split broods under constant low or high food supply, or in treatments in which the food supply was reciprocally reversed at a fixed point in time. Based on strong fecundity-selection for large female size (Higgins \& Goodnight 2011; Kuntner et al. 2012), we predicted effective catch-up growth after treatment reversal in initially food-restricted females to compensate the preceding deficits. As Nephila males generally benefit from protandry (Danielson-Francois et al. 
143 2012; Kasumovic et al. 2009), selection should act against an exceedingly delayed development 144 in males. Furthermore, flexible mating strategies have been found to balance reproductive 145 success between differently-sized competitors (Neumann \& Schneider 2015). Therefore, we 146 assumed weaker selection on large male size and predicted less effective catch-up growth in 147 males.

148 Following the rearing treatments, we used a subset of adult females to measure life-time 149 fecundity (LTF), thereby providing a direct test concerning the adaptive significance of growth

150

151

152

153

154

155

156

157

158

159

160

161

162

163

164

165

166

167

168

169

170

171 compensation, which is often omitted in empirical studies (Dmitriew 2011; Hector \& Nakagawa 2012). We predicted growth compensation to result in equivalent numbers of offspring in initially food-restricted females compared to constantly well-fed females.

As another measure of fitness, we tested whether growth compensation affected the postmaturation lifespan and hence the potential time-frame of reproduction in both sexes. Finally, we report treatment-related mortality and analyse genotype-by-treatment interactions as a potential cause of the remarkable variation of life-history traits in our model system.

\section{Material \& Methods}

Developmental duration, body size and weight, pre-maturation mortality

We collected eight gravid females near Cradock, Eastern Cape, South Africa in March, 2008. Field-collected females were transferred to the laboratory and housed individually in $60 \times 60$ $\mathrm{cm}$-sized Perspex frames. We maintained females under standardized conditions and all of them built viable egg sacs that were incubated in air-vented plastic containers until the offspring hatched (see Schneider et al. 2011 for our standard methods concerning housing, feeding, and watering of spiders as well as temperature conditions). The hatchlings were separated at very small body size $(2-4 \mathrm{~mm}$ ) before they had reached the third instar (the first two moults in Nephila spiders occur inside the egg sac). Separated spiders were housed in small plastic cups but were transferred to larger cups as they increased in body size. We haphazardly allocated the study animals to the following feeding treatments: (1) High-High, (2) High-Low, (3) 
172 Low-High, and (4), Low-Low. Equal numbers of spiders from individual maternal lineages were 173 used in each treatment. Spiders in the High-High treatment were provided with ad libitum food 174 over the entire duration of development to maturity, whereas spiders in treatment Low-Low 175 were kept at low-food conditions throughout the experiment. Study animals in treatment High176 Low received ad libitum food during a fixed period of four weeks (defined as early experimental conditions) but were kept under low-food conditions in the period following the first four weeks (defined as late experimental conditions). The inversed pattern was adopted in treatment Low-High. The spiders were fed Drosophila and Calliphora flies. Low-food conditions conform to 4 Drosophila flies per week during early experimental conditions and 6-10 Drosophila flies (depending on the spider's size) per week during late experimental conditions, respectively. Low-food spiders large enough to eat Calliphora received 2 flies per week. Drosophila flies were raised on Carolina Biological Supply instant Drosophila medium Formula 4-24, which was enriched with additional nutrients, especially protein and vitamins. For this purpose, we mixed the medium with commercial high quality dog food according to a study by Mayntz \& Toft (2001), which demonstrated positive effects on growth and survival in a wolf spider fed with flies cultivated on this specific mixture. Calliphora flies were obtained by incubating fully grown larvae purchased from a commercial supplier. All study animals were reared in a daylight lab and hence were exposed to slight photoperiod changes. We checked the spiders on five days per week and tracked the development of each individual by recording the following data: sex, duration of development from the start of the experiment to maturation, weight at completion of the early experimental period, adult weight and adult body size (given as patella-tibia length).

As morphology-based sex-determination is impossible in small juvenile spiders, individuals could be sexed only at larger developmental stages in the late experimental period, but 85 spiders died unsexed. Immature males were identified by their swollen pedipalps indicating the ongoing transformation into copulatory organs; the lack of this trait in juveniles with a body 
201

202 In addition to developmental modifications, we analysed treatment-related effects on adult 203 longevity. For this purpose, we chose 137 males and 251 females across treatments upon

204

205

206

207

208

209

210

211

212

213

214

215

216

217

218

219

220

221

222

223

224

225

226

227

228

reaching maturity. The spiders were maintained on our regular laboratory feeding schedule irrespective of the developmental feeding treatment experienced before. Spiders were chosen randomly; paying attention, however, to exclude animals to be used in the mating experiments (see 'Life-time fecundity and hatching success') or in our general breeding schedule. The remaining study animals were killed by hypothermia after reaching maturity and preserved at $80^{\circ} \mathrm{C}$. In total, 1280 spiders were used in this study, of which 30 disappeared and another three were accidently killed during daily routine at early juvenile stages.

\section{Life-time fecundity and hatching success}

We randomly chose 38 adult females originating from the treatments High-High $(N=14)$, LowHigh $(N=11)$, and Low-Low $(N=13)$ to investigate whether compensatory growth enables females to overcome a period of poor feeding conditions during juvenile development and achieve a reproductive outcome equivalent to constantly well-fed females. We did not include High-Low females in this experiment (females in treatments High-Low and Low-Low did not differ significantly in developmental duration and size; see results). Females were maintained on our regular feeding schedule. We randomly chose adult males from the High-High feeding treatment to arrange mating trials. Prior to mating, each female was transferred to a Perspex frame (measuring $60 \times 60 \times 12 \mathrm{~cm}$ ) and given at least one day to build an orb-web, which is necessary for courtship and mating to take place. We positioned an unrelated male on the upper frame threads of the web. Each virgin couple was allowed to copulate once in a predefined period of 3 hours. If copulation did not occur within the given time, we excluded the male from the study and arranged a second mating trial with a different male at a later date (each male was used only once). Six females remained unmated after the second trial and were excluded from the study. 
229

230

231

232

233

234

235

236

237

238

239

240

241

242

243

244

245

246

247

248

249

250

251

252

253

254

255

256

257

At the beginning of each trial, the female received one Calliphora fly (males prefer mating with feeding females; Schneider et al. 2011). We measured the duration of copulation and removed the spiders from the web afterwards. Females were maintained in Perspex frames to build egg sacs until they died of age. Four females did not build egg sacs at all, despite apparently normal copulations. The egg sacs produced were incubated in air-vented plastic containers and preserved in alcohol after approximately five weeks. We carefully opened each egg sac and assessed the number of normally developed spiderlings, undeveloped eggs, and total clutch size. All experiments were carried out at the Zoological Institute, University of Hamburg.

\section{Statistical analyses}

The study animals originated from eight maternal lineages from which we allocated equal numbers of individuals to each rearing-treatment. As a premise for further analysis, we tested if family lineages were evenly distributed among individuals that had passed through the feeding treatments and finally matured. The test confirmed no significant differences in the numbers of individuals originating from different family lineages between our feeding treatments (G-tests: males: $\chi^{2}=15.16, P=0.82 ; N=362$; females: $\left.\chi^{2}=19.24, P=0.57 ; N=559\right)$. We tested predictions with respect to adult body size, body mass, developmental durations, life-time fecundity (LTF), and post-maturation longevity using t-tests for normal data with equal variances and non-parametric Wilcoxon or Kruskal-Wallis tests if data diverged from these assumptions (indicated by Shapiro- and Bartlett's tests). Results are given as means $\pm \mathrm{SE}$, providing medians and interquartile ranges (IQRs) for non-parametric tests. Complementary post-hoc analyses were performed using pairwise Steel-Dwass tests that correct for Type I error inflation in multiple comparisons. We performed three linear mixed models to analyse sexspecific and family-related effects of our feeding treatments on development and growth. We tested effects of the variables 'Early treatment' (High or Low), 'Family lineage', and 'Sex' on body mass after completion of the early experimental period with a model containing all three variables and the interactions between Early Treatment and Family linage as well as between 
258 Early treatment and Sex. Models on total developmental duration (beginning with the day on 259 which hatchlings were separated and allocated to individual treatments) and adult body size 260 were equally specified with 'Treatment' (early and late conditions), Family, and Sex as well as 261 the respective interaction terms. The variable 'Start date' (the day of allocation to experimental 262 treatments) was entered into the models as a random effect to account for a potential 263 influence of photoperiod on development (Start date had nine levels ranging from June 11 to 264 July 25, 2008). Body mass and developmental duration were log-transformed to improve the fit 265 of the models. We analysed variation in LTF with a standard least-square model containing the interaction between Treatment and the number of clutches produced. All analyses in this study were conducted in JMP Pro 13 (SAS Institute Inc., Carey, NC, USA). Effect tests for individual variables in JMP are based on ANOVA-model comparisons between the full model and a reduced model lacking the respective variable. Additional statistical tests are denoted in the results section. Sample sizes within experiments may differ due to missing data.

\section{Results}

273

IMPLICATIONS OF EARLY EXPERIMENTAL CONDITIONS

275

Mortality rates during the first four weeks of the experiment did not differ significantly between early treatments; 59 of 626 spiders died under high feeding conditions $(9.4 \%)$ and 74 of 630 spiders died under low feeding conditions (11.8\%) (G-test: $\left.\chi^{2}=1.79, P=0.18 ; N=1256\right)$. (Sex-determination is impossible in small juvenile spiders; hence mortality rates were analysed independent of sex.)

In both sexes, body mass after the first four weeks differed considerably between early low 282 and high feeding conditions. Males weighed $2.6 \pm 0.11 \mathrm{mg}$ at the end of the early low food period (median = $2.35 \mathrm{mg}, \mathrm{IQR}=1.65$ ); significantly less than those reared under early high feeding conditions, weighing 9.56 $\pm 0.43 \mathrm{mg}$ (median $=8.26 \mathrm{mg}, \mathrm{IQR}=6.46$ ) (Wilcoxon test: $\mathrm{Z}=$ 13.96, $P<0.0001 ; N=363$ ). In females, early low feeding conditions resulted in a body mass of 286 $4.08 \pm 0.12 \mathrm{mg}$ (median $=3.84 \mathrm{mg}, \mathrm{IQR}=2.15)$, whereas early high-feeding females weighed 
$28723.95 \pm 0.68 \mathrm{mg}($ median $=22.25 \mathrm{mg}, \mathrm{IQR}=17)($ Wilcoxon test: $Z=21.26, P<0.0001 ; N=665)$.

288 We conducted a linear mixed model to test for sex-specificity of juvenile growth as well as a 289 potential family-relatedness of growth responses. The model revealed highly significant effects 290 of the interactions between Early feeding treatment and Family lineage as well as between 291 Early treatment and Sex on the spiders' body mass at completion of the early experiment 292 (Table 1).

293

294

IMPLICATIONS OF FULL EXPERIMENTAL CONDITIONS

295

296

Pre-maturation mortality

297

298

299

We analysed pre-maturation mortality in spiders that survived to experience both early and late experimental conditions and found distinctly different mortality rates (G-test: $\chi^{2}=29.1, P<$ 300 $0.0001 ; N=1114 ;$ Table 2).

301

As mortality rates during the first four weeks did not differ between early high and low 302 feeding conditions (see above), mortality differences concerning full experimental conditions may have solely been caused by late conditions. Pairwise between-treatment comparisons corroborated this assumption; irrespective of early feeding conditions, pre-maturation 305 mortality rates differed significantly in treatment pairs exhibiting different late feeding conditions, but not in treatment pairs in which late feeding conditions were identical (Table 2).

Adaptive catch-up growth

309

In accordance with our predictions, late developmental durations in Low-High females significantly exceeded those of females in the High-High treatment (Late female developmental duration L-H: mean = 57.39 \pm 1.04 days, median = 54 days, IQR $=8$ ); $\mathrm{H}-\mathrm{H}:$ mean $=46.72 \pm 0.59$ days, median $=46$ days, IQR $=8.75 ;$ Wilcoxon test: $Z=9.81, P<0.0001 ; N=292$ ). This delay of development resulted in full compensation of adverse early feeding conditions (Fig. 1). Females 
$31612.24 \pm 0.13 \mathrm{~mm}$, median $=12.22 \mathrm{~mm}, \mathrm{IQR}=1.9 ; \mathrm{H}-\mathrm{H}:$ mean $=12.45 \pm 0.59 \mathrm{~mm}$, median $=12.32$ $317 \mathrm{~mm}, \mathrm{IQR}=1.39 ;$ Wilcoxon test: $\mathrm{Z}=0.81, P=0.416 ; N=283$; Female adult weight $\mathrm{L}-\mathrm{H}:$ mean $=$

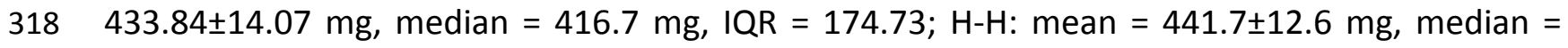
$319410.83 \mathrm{mg}, \mathrm{IQR}=159.67$; Wilcoxon test: $\mathrm{Z}=0.22, P=0.826 ; N=282$ ).

320 Males in the Low-High treatment also delayed development compared to High-High males 321 (Late male developmental duration L-H: mean $=45.46 \pm 1.16$ days, median $=45$ days, IQR $=15$; $322 \mathrm{H}-\mathrm{H}:$ mean = 33.11 \pm 1.05 days, median = 31 days, IQR = 11; Wilcoxon test: $\mathrm{Z}=7.56, P<0.0001$; $323 N=190)$. In contrast to females, however, prolonged development did not fully compensate 324 differences in male adult size and body mass (Male adult size $\mathrm{L}-\mathrm{H}$ : mean $=4.95 \pm 0.11 \mathrm{~mm} ; \mathrm{H}-\mathrm{H}$ : 325 mean $=5.62 \pm 0.09 \mathrm{~mm}$; t-test: $t=4.86, P<0.0001 ; N=184$; Male adult weight L-H: mean = $32626.59 \pm 1.09 \mathrm{mg}$, median $=25.25 \mathrm{mg}, \mathrm{IQR}=13.81 ; \mathrm{H}-\mathrm{H}:$ mean $=34.23 \pm 1.03 \mathrm{mg}$, median $=32.57$ $\mathrm{mg}, \mathrm{IQR}=14.05 ;$ Wilcoxon test: $Z=5.06, P<0.0001 ; N=191$ ) (Fig. 1).

Developmental durations and adult size in the remaining treatments

Complementary post-hoc analyses of the remaining treatment-pairs confirmed the overall limiting effects of low experimental nutrition on development and growth (Table 3). Females in the Low-Low and High-Low treatments took much longer to mature and were still very much smaller than females in the two other treatments (Fig. 2, Table 3).

Males responded differently from females, as they took longer to reach adulthood and matured at smaller size in the Low-Low treatment compared to High-Low males (Fig. 2, Table 3). Further different from females, males showed intermediate developmental durations and adult size in the High-Low and Low-High treatments relative to Low-Low and High-High males

(Fig. 2), indicating less adverse effects of late low feeding conditions in males. In both sexes, High-High conditions resulted in shortest developmental durations as well as largest adult size (Fig. 2). 
345 We used linear mixed models to test whether phenotypic variation regarding developmental 346 duration and adult body size can be attributed, in part, to family-specific plastic responses and 347 to ascertain overall sex differences with respect to development and growth. The models were 348 specified with Treatment, Sex, and Family lineage as well as the Treatment-by-Sex and 349 Treatment-by-Family lineage interactions as explanatory variables ('Start date' was included as 350 a random effect to account for slight photoperiod changes; see methods). Highly significant 351 effects of both interactions confirmed sex-specific development and family-specific plasticity 352 (Table 4).

353

POST-MATURATION IMPLICATIONS

355

356

Life-time fecundity and hatching success

357

358

Females originating from the Low-High treatment delayed maturation, but achieved similar adult body size and weight as High-High females through catch-up growth (see above). We predicted equivalent fecundity in Low-High females compared to High-High females and tested differences between feeding treatments High-High, Low-High, and Low-Low (we did not include High-Low females; High-Low and Low-Low females did not differ significantly in developmental duration and size; see Table 2). Fecundity was measured as the total number of eggs (comprising hatched and undeveloped eggs) produced by each female during her entire reproductive lifespan (Life-time fecundity, LTF). The mean number of clutches was $2.82 \pm 0.25$ (range 1-6) and did not differ significantly between treatments (pairwise Tukey-Kramer HSD tests: $P>0.1 ; N=28$ ). Females originating from the Low-High treatment achieved the highest LTF of all treatments (LTF L-H $=2832.8 \pm 448.02 ; N=10$ ), producing more eggs than the HighHigh females (LTF $\mathrm{H}-\mathrm{H}=2071.64 . \pm 320.12, N=11$ ) and about twice as many as females originating from the Low-Low treatment (LTF L-L $=1343.86 \pm 262.65 ; N=7$ ). A linear model showed that the interaction between treatment and the number of clutches explained a large proportion of variation in $\operatorname{LTF}\left(F=4.154, P=0.03\right.$, adjusted $\left.R^{2}=0.83\right)$. The model suggested that 
374 Low-Low females were unable to achieve an equivalent increase of fecundity (Fig. 3). A Tukey375 Kramer HSD test performed on model least square means showed significant differences in LTF 376 between the Low-Low treatment and both other treatments (pairwise comparisons: $\mathrm{L}-\mathrm{H}-\mathrm{H}-\mathrm{H}$ : $P=0.264, N=21 ; \mathrm{L}-\mathrm{H}-\mathrm{L}-\mathrm{L}: P=0.0002, N=17 ; \mathrm{H}-\mathrm{H}-\mathrm{L}-\mathrm{L}: P=0.005, N=18)$.

378 Treatment effects on LTF did not correspond to absolute hatching success in our study. Although the total number of hatchlings produced differed considerably between treatments, variation was high and the differences were not significant (Number of hatchlings $\mathrm{H}-\mathrm{H}$ : mean $=$ 962.45 \pm 290.47 , median $=701, \mathrm{IQR}=2287 ; \mathrm{L}-\mathrm{L}:$ mean $=421.57 \pm 133.05$, median $=528, \mathrm{IQR}=$ 738; L-H: mean = 1726.2 \pm 364.68, median $=2138$, IQR $=2070.75 ;$ Kruskal-Wallis test: $\chi^{2}=4.95, P$ $=0.084 ; N=28$ ). We also asked if feeding regimes affected relative hatching success (i.e. the proportions of normally developed hatchlings and undeveloped eggs), but again there were no significant differences between treatments (Proportions hatched $\mathrm{H}-\mathrm{H}$ : mean $=46.9 \pm 9.86$, median $=57.58, \mathrm{IQR}=71.81 ; \mathrm{L}-\mathrm{L}:$ mean $=38.01 \pm 12.76$, median $=35.31, \mathrm{IQR}=53.1 ; \mathrm{L}-\mathrm{H}:$ mean $=$ 55.41 \pm 10.41 , median $=56.56, \mathrm{IQR}=49.19 ;$ Kruskal-Wallis test: $\left.\chi^{2}=1.5, P=0.47 ; N=28\right)$.

A post-hoc test revealed a positive correlation between copulation duration and the total number of hatchlings $\left(F=18.97, P<0.001, N=28, R^{2}=0.42\right)$. In nature, female $N$. senegalensis are polyandrous and females have been shown to mate repeatedly in other studies (Neumann \& Schneider 2015; Schneider \& Michalik 2011). In this study, single copulations were probably insufficient to fertilize all eggs produced by a female.

Post-maturation longevity

We tested whether a period of juvenile food restriction and subsequent catch-up growth reduced the study animals' post-maturation lifespan, but found no significant effects in both sexes (Male adult lifespan $\mathrm{H}-\mathrm{H}$ : mean = 148.08 \pm 7.85 days, median = 144 days, IQR = 46; L-L: mean $=169.91 \pm 9.98$ days, median $=178$ days, IQR $=75 ; \mathrm{L}-\mathrm{H}:$ mean $=150.98 \pm 5.77$ days, median 400 = 147 days, IQR = 34; H-L: mean = 147.31 \pm 8.53 days, median = 150.5 days, IQR = 38; KruskalWallis test: $\chi^{2}=4.83, P=0.185 ; N=137$; Female adult lifespan $\mathrm{H}-\mathrm{H}$ : mean $=61.55 \pm 4.09$ days, 402 median $=60$ days, IQR $=55 ; \mathrm{L}-\mathrm{L}:$ mean $=72.1 \pm 4.61$ days, median $=69.5$ days, IQR $=40 ; \mathrm{L}-\mathrm{H}$ : 
403 mean $=57.75 \pm 3.9$ days, median $=54$ days, IQR $=34.5 ; \mathrm{H}-\mathrm{L}:$ mean $=63.08 \pm 5.46$ days, median $=$ 40461 days, IQR = 38; Kruskal-Wallis test: $\chi^{2}=4.67, P=0.198 ; N=251$ ).

405

406

\section{Discussion}

407

408

Female Nephila senegalensis reared under food restriction in early development (Low-High females) used catch-up growth to counteract the restriction period and attain an adult body size and mass similar to those reared under constant food abundance (High-High females). As expected, Low-High females delayed maturation to fully compensate previous growth deficits. Size compensation had to be charged against an average developmental delay of 9-12 days; extending development by approximately $23 \%$ compared to High-High females. This additional investment in time and growth enabled Low-High females to achieve a life-time fecundity (LTF) equivalent to High-High females; substantially exceeding LTF in constantly food-restricted females (Low-Low females). These findings further corroborate strong fecundity selection on large female size in Nephila. Consistent with our predictions, males did not implement catch-up growth as efficiently, showing incomplete compensation of body size. Although Low-High males delayed their development by 10-14 days, extending development by approximately $37 \%$ compared to High-High males, they matured significantly smaller than the latter. The divergence between the sexes likely reflects generally weaker selection on large male size and hence compensatory ability, but may also indicate a stronger trade-off between timely maturation and growth in males. Juvenile food restriction and compensatory development did not affect the post-maturation lifespan in either sex.

The benefits of catch-up growth have to be offset against costs of a delayed development, which certainly affect fitness under natural conditions. Environmental parameters, such as temperature, food abundance and weather conditions, may generally fall off in quality with the season approaching its end (Hut et al. 2013). This constitutes an 'end-of-season penalty' for late maturing individuals in semelparous species (De Block et al. 2008; Higgins 2000). Determinate growth and annual life cycles eliminate the opportunity to optimize body size after sexual 
431 maturation and to increase fitness in future reproduction, forcing animals into a narrow time 432 frame in which to grow and to reproduce.

433 In N. senegalensis, females produce long-lasting egg sacs which overwinter and hatch in the 434 following spring. The spiders generally mature in late summer and early autumn to experience 435 a relatively short reproductive period that declines with increasingly adverse weather 436 conditions in late autumn (Neumann \& Schneider, pers. observations). Such strong seasonality 437 generates several trade-offs to cope with. For instance, a prolonged pre-maturation 438 development entails a higher predation-risk (Blanckenhorn 2000), but at the same time, large 439 Nephila females outgrow the risk of being preyed upon by various invertebrate predators and 440 parasitoids (Chase 1999; Higgins 2002). However, they may become more attractive to larger 441 vertebrate predators. To make use of large body size in terms of fecundity also requires an 442 increased amount of food and more time to produce the large numbers of eggs that can 443 potentially be laid in multiple clutches (Higgins 2000; Neumann \& Schneider 2015). Therefore, 444 the adaptive significance of catch-up growth may vary between environments, for example, depending on predation pressure and the level of physical disturbance caused by extreme weather events (Higgins 2000). Females are hence expected to integrate environmentally-cued information into implementing catch-up growth.

The prospects of fitness optimization through catch-up growth seem to be more limited in males, which showed less growth compensation despite a significant developmental delay. In Nephila, body size has often been shown to play a role in male-male competition (Kuntner \& Elgar 2014), but the relationship between physical dominance and increased reproductive success has been oversimplified in the past. Indeed, large males may successfully execute their physical strength in specific competitive settings, e.g. in mating contests involving multiple males (Rittschof 2010). On the other hand, there is evidence from both experimental work (Neumann \& Schneider 2015; Schneider \& Elgar 2005) and theoretical modelling (Rittschof et al. 2012) that small and medium-sized males adopt alternative mating strategies that balance overall paternity in competition with large rivals. Furthermore, the modelling approach suggested a decrease of average male reproductive success over the course of the season 459 (Rittschof et al. 2012). This might be due to the fact that unmated females become increasingly 
460 rare and mated males may guard their females against successive competitors (Cohn et al. 461 1988; Schneider et al. 2008). In addition, late maturing females are generally smaller and hence 462 less fecund than early females (Higgins 2000; Miyashita 1986). These factors may favour 463 protandry and amplify the trade-off between developmental time and adult size in males. The 464 importance of a timely maturation was further supported in an experimental study, showing 465 that male $N$. senegalensis are able to adjust the duration of their subadult instar (i.e. the last developmental stage preceding maturity) to the presence of receptive females by shifting maturation in the order of several days (Neumann \& Schneider 2016). Immature males use female silk (or probably silk-borne pheromones) as a cue to perceive females. Such plastic finetuning of life-history may increase males' chances to locate receptive females in time and avoid male-male competition, thus further relaxing selection on large male size. However, since males at least showed incomplete catch-up growth, such compensation to the minor extant should nevertheless be adaptive. Males may use moderate catch-up growth to disperse unavoidable fitness costs between both traits affected by early food restriction (the duration of development and adult body size), rather than to mend only one of them.

Sex-specific differences with respect to adaptive developmental modifications addressed in this study probably result from an evolutionary history of divergent size selection, giving way to sexual size dimorphism (SSD). Extreme reversed SSD in Nephila is likely facilitated by the genetic uncoupling of body size between the sexes (Kuntner \& Elgar 2014). The task of explaining the evolution and maintenance of extreme SSD requires identification of sex-related selection pressures. In our experiment, individuals of both sexes developed more slowly and matured smaller in the Low-Low treatment than those in the High-High treatment, but apart from that, we observed considerable differences between the sexes. Males in the High-Low treatment showed similar life-history responses as Low-High males; both treatments resulting in intermediate average developmental duration and adult size relative to High-High and Low-Low males.

In females, however, the respective treatments had markedly different effects. In High-Low females, the late decrease of food supply resulted in severe limitations, as these females 488 neither matured significantly faster nor achieved a larger size than Low-Low females. Thus, in 
489 contrast to males, females in the High-Low treatment significantly fell behind Low-High females

490 in terms of developmental compensation, probably bearing high fitness costs. The fact that

491 development and adult size did not differ between High-Low and Low-High males indicates less

492 adverse effects of late-development food stress in males. A previous study addressing sex

493 differences in Nephila with respect to food quantity showed that females demand an increased

494 food supply and especially require more food than males to reach sexual maturation (Higgins \&

495 Goodnight 2010). The reduction of energetic requirements associated with small male size may

496 therefore help to avoid fitness costs under food stress (Blanckenhorn et al. 1995); potentially

497 representing an important evolutionary driver to promote the uncoupling of body size between

498 the sexes in spiders.

499 Although females in the Low-Low and High-Low treatments faced significant limitations

500 regarding pace of development and adult body size, it is important to note that a large

501 proportion of those females were still able to reach sexual maturity. Moreover, Low-Low

502 females included in our mating trials and analyses of fecundity proved to be able to reproduce;

503 albeit at a lowered level. Such small females that are also observed in natural populations may

504 be able to escape reproductive failure by making "the best of a bad job" (Higgins et al. 2011).

505 These findings indicate that the general trade-off between the time invested in growth and the

506 resulting adult size can be enforced substantially by periods of food limitation. Favourable

507 conditions, on the other hand, may alleviate this trade-off, as males and females in the High-

508 High treatment took the shortest average developmental duration to reach the largest average 509 body size.

510 Irrespective of sex and treatment, variation of developmental duration and adult size was

511 high. Our analyses revealed that these life-history traits were modulated by an interaction

512 between experimental treatments (i.e. the spiders' environment) and family lineage,

513 representing inherited genetic variation and/or maternal effects. Hence, part of the variation in

514 these traits was caused by family-specific responses to feeding conditions, which has also been

515 observed in other web-building spiders (e.g. Kleinteich \& Schneider 2010).

516 The ability to survive under different feeding conditions is a basic requirement to implement

517 adaptive developmental plasticity against impending costs of food restriction. Our results 
518 suggest that juvenile $N$. senegalensis are well able to survive a period of poor feeding 519 conditions in early developmental stages. Although early high- or low-food conditions 520 significantly influenced the study animals' growth, these differences did not affect the chance 521 of survival. Very low metabolic rates in general enable spiders to subsist on low quantities of 522 food (Foelix 2011; Mayntz et al. 2003). It is possible that phenotypic plasticity is also used to 523 adjust metabolic rates to present conditions in order to survive food stress (Collatz \& 524 Mommsen 1975). Larger juvenile stages, however, develop higher nutritional requirements to 525 maintain all vital physiological functions, making fluctuations in food supply more dangerous 526 (Higgins \& Goodnight 2010). Accordingly, we recorded a significant increase of mortality rates 527 in spiders experiencing low-food conditions during late development.

528 Adaptive catch-up growth clearly bears costs of a delayed sexual maturity, but may also 529 involve intrinsic long-term costs arising from developmental compensation, e.g. through partial 530 elevated growth (Hector \& Nakagawa 2012; Metcalfe \& Monaghan 2001). Physiological stress 531 can even reduce an organism's longevity (English \& Uller 2016; Hornick et al. 2000), but our 532 feeding treatments had no effect on the spiders' adult lifespan. In contrast, permanent juvenile 533 food restriction reduced adult longevity in another araneid, the Bridge spider, Larinioides 534 sclopetarius (Kleinteich et al. 2015). As in Nephila, female Bridge spiders delayed development and grew as large as control females; hence there was no apparent elevated growth and it remains unclear whether adverse effects on longevity resulted from dietary restrictions or the compensatory mechanism itself. Although female Bridge spiders reared under food restriction fully compensated adult size, their fecundity lagged behind control females, because they produced smaller clutches (Kleinteich et al. 2015). Such findings point to limitations of fitness approximations based on size measurements. It is thus important that our study could not only confirm the proposed size-increase through delayed maturation (Higgins 1992), but also evaluated LTF as a direct consequence of experimentally induced developmental responses.

While our results are in accordance with our predictions, findings in other studies addressing compensatory development in size-dimorphic species diverged from predictions in whole or in part. For example, similar to our model system, fecundity-selected females in the mosquitofish, 
547 restriction, whereas minor catch-up growth was expected in the much smaller males whose 548 fitness was proposed to depend less on large size. Different from predictions, however, both 549 sexes delayed maturation and grew as large as control fish (Livingston et al. 2014). Male 550 mosquitofish exhibit large size variation in nature and the authors suggest that size-related 551 fitness consequences might depend on variable external conditions, including the social 552 environment. Male developmental strategies may thus be influenced by population density and 553 the intensity of male-male competition (or cues of such conditions) (Livingston et al. 2014). It is 554 important, in general, to note that other environmental variables may often interact with food 555 supply to induce specific responses, which is challenging to incorporate into experimental work 556 (Davidowitz et al. 2004; Stillwell \& Davidowitz 2010).

557 In the pholcid spider Pholcus phalangioides, presenting a rare case of male-biased sexual size558 dimorphism in spiders (Uhl, 1994a), males benefit from both timely maturation and large body 559 size by avoiding male-male competition, or by succeeding in it (Schaefer \& Uhl 2003). Food560 restricted males were predicted to use developmental plasticity to increase body size either by delaying development or through accelerated growth. However, although males took longer to mature than control siblings, they could not catch up in terms of adult size (Uhl et al. 2004). Males were apparently unable to resolve the trade-off between the benefits of protandry and advantages of large size under dietary restrictions (Uhl et al. 2004). Similarly to our findings, the observed developmental response may reflect a way of dispersing disadvantages with respect to developmental duration and adult size across both traits. It would be worthwhile, in general, to evaluate whether this kind of 'bet-hedging' through intermediate life-history traits in moderate catch-up growth is truly adaptive and how external conditions may influence developmental responses. Future studies addressing these aspects should integrate field-based knowledge regarding existing phenotypes, the social environment, and time regime, and preferably include potential interactions between multiple environmental factors that might be

572 involved in the expression of plastic traits.

573

\section{Conclusions}


576 Male and female Nephila senegalensis performed significantly different with respect to catch577 up growth. Our study indicates strong fecundity selection on females, resulting in efficient 578 growth compensation and hence prevention of fecundity-related fitness costs. Matching our 579 predictions, catch-up growth in males did not evolve to the same capacity as in females. 580 Relaxed selection on large male size and a stronger trade-off between costs of a delayed 581 maturation and size-related benefits were reflected in incomplete growth compensation.

582 Nonetheless, the moderate degree of catch-up growth in males is likely adaptive in dispersing 583 unavoidable costs of food restriction across affected traits. The adaptive value of moderate 584 compensatory development and the potential adjustment of such mechanisms to 585 environmentally or socially cued conditions should be addressed in future studies.

586

\section{Acknowledgements}

588

589

590

We are grateful to Tomma Dirks, Angelika Taebel-Hellwig, Stefanie Zimmer, Janine Helms, and Jessica Suhr for invaluable help in the rearing of study animals and data recording, Claudia

Drees and Luca Neumann for graphing advice, and Matthias Foellmer and an anonymous

reviewer for valuable comments on the manuscript.

593

594

References

595

596

597

598

599

600

601

602

603

604

605

606

607

608

609

610

Abrams PA, Leimar O, Nylin S, and Wiklund C. 1996. The effect of flexible growth rates on optimal sizes and development times in a seasonal environment. American Naturalist 147:381-395. $10.1086 / 285857$

Arnold KE, Blount JD, Metcalfe NB, Orr KJ, Adam A, Houston D, and Monaghan P. 2007. Sex-specific differences in compensation for poor neonatal nutrition in the zebra finch Taeniopygia guttata. Journal of Avian Biology 38:356-366. 10.1111/j.2007.0908-8857.03818.x

Barreto RE, Moreira PSA, and Carvalho RF. 2003. Sex-specific compensatory growth in food-deprived Nile tilapia. Brazilian Journal of Medical and Biological Research 36:477-483. 10.1590/s0100$879 \times 2003000400009$

Bauerfeind SS, and Fischer K. 2005. Effects of food stress and density in different life stages on reproduction in a butterfly. Oikos 111:514-524. 10.1111/j.0030-1299.2005.13888.x

Blanckenhorn WU. 2000. The evolution of body size: What keeps organisms small? Quarterly Review of Biology 75:385-407. 10.1086/393620

Blanckenhorn WU. 2005. Behavioral causes and consequences of sexual size dimorphism. Ethology 111:977-1016. 10.1111/j.1439-0310.2005.01147.x 
611

612

613

614

615

616

617

618

619

620

621

622

623

624

625

626

627

628

629

630

631

632

633

634

635

636

637

638

639

640

641

642

643

644

645

646

647

648

649

650

651

652

653

654

655

656

Blanckenhorn WU, Dixon AFG, Fairbairn DJ, Foellmer MW, Gibert P, van der Linde K, Meier R, Nylin S, Pitnick S, Schoff C, Signorelli M, Teder T, and Wiklund C. 2007. Proximate causes of Rensch's rule: Does sexual size dimorphism in arthropods result from sex differences in development time? American Naturalist 169:245-257. 10.1086/510597

Blanckenhorn WU, Preziosi RF, and Fairbairn DJ. 1995. Time and energy constraints and the evolution of sexual size dimorphism - to eat or to mate. Evolutionary Ecology 9:369-381. 10.1007/bf01237760

Bonneaud C, Marnocha E, Herrel A, Vanhooydonck B, Irschick DJ, and Smith TB. 2016. Developmental plasticity affects sexual size dimorphism in an anole lizard. Functional Ecology 30:235-243. 10.1111/1365-2435.12468

Chase JM. 1999. To grow or to reproduce? The role of life-history plasticity in food web dynamics. American Naturalist 154:571-586.

Cheng RC, and Kuntner M. 2015. Disentangling the Size and Shape Components of Sexual Dimorphism. Evolutionary Biology 42:223-234. 10.1007/s11692-015-9313-z

Chin EH, Storm-Suke AL, Kelly RJ, and Burness G. 2013. Catch-up growth in Japanese quail (Coturnix japonica): relationships with food intake, metabolic rate and sex. Journal of Comparative Physiology B-Biochemical Systemic and Environmental Physiology 183:821-831. 10.1007/s00360013-0751-6

Christenson TE, and Goist KCJ. 1979. Costs and benefits of male-male competition in the orb weaving spider, Nephila clavipes. Behavioral Ecology and Sociobiology 5:87-92.

Cohn J, Balding FV, and Christenson TE. 1988. In defence of Nephila clavipes: postmate guarding by the male golden orb-weaving spider. Journal of Comparative Physiology 102:319-325.

Collatz KG, and Mommsen T. 1975. Effects of short and long-term starvation on body composition and metabolic rate of the spider Tegenaria atrica Koch (Agelenidae). Journal of Comparative Physiology 98:205-212.

Dahl E, Orizaola G, Nicieza AG, and Laurila A. 2012. Time constraints and flexibility of growth strategies: geographic variation in catch-up growth responses in amphibian larvae. Journal of Animal Ecology 81:1233-1243. 10.1111/j.1365-2656.2012.02009.x

Danielson-Francois A, Hou C, Cole N, and Tso IM. 2012. Scramble competition for moulting females as a driving force for extreme male dwarfism in spiders. Animal Behaviour 84:937-945.

Davidowitz G, D'Amico L, and Nijhout HF. 2003. Critical weight in the development of insect body size. Evolution \& Development 5:188-197. 10.1046/j.1525-142X.2003.03026.x

Davidowitz G, D'Amico L, and Nijhout HF. 2004. The effects of environmental variation on a mechanism that controls insect body size. Evolutionary Ecology Research 6:49-62.

De Block M, McPeek MA, and Stoks R. 2008. Life history plasticity to combined time and biotic constraints in Lestes damselflies from vernal and temporary ponds. Oikos 117:908-916. 10.1111/j.2008.0030-1299.16603.x

Dmitriew CM. 2011. The evolution of growth trajectories: what limits growth rate? Biological Reviews 86:97-116. 10.1111/j.1469-185X.2010.00136.x

Elgar MA, Bruce MJ, and de Crespigny FEC. 2003. Male mate choice and patterns of paternity in the polyandrous, sexually cannibalistic orb-web spider Nephila plumipes. Australian Journal of Zoology 51:357-365.

Elgar MA, and Fahey BF. 1996. Sexual cannibalism, competition, and size dimorphism in the orb-weaving spider Nephila plumipes Latreille (Araneae, Araneoidea). Behavioral Ecology 7:195-198.

English S, and Uller T. 2016. Does early-life diet affect longevity? A meta-analysis across experimental studies. Biology Letters 12. 10.1098/rsbl.2016.0291 
657

658

659

660

661

662

663

664

665

666

667

668

669

670

671

672

673

674

675

676

677

678

679

680

681

682

683

684

685

686

687

688

689

690

691

692

693

694

695

696

697

698

699

700

701

702

703

704

Fernandez-Montraveta C, and Moya-Larano J. 2007. Sex-specific plasticity of growth and maturation size in a spider: implications for sexual size dimorphism. Journal of Evolutionary Biology 20:16891699. 10.1111/j.1420-9101.2007.01399.x

Foelix RF. 2011. Biology of Spiders. New York: Oxford University Press.

Foellmer MW, and Fairbairn DJ. 2004. Males under attack: sexual cannibalism and its consequences for male morphology and behaviour in an orb-weaving spider. Evolutionary Ecology Research 6:163181.

Foellmer MW, and Moya-Laraño J. 2007. Sexual size dimorphism in spiders: patterns and processes. Sex, Size and Gender Roles: evolutionary studies of sexual size dimorphism:71-81.

Foster RG, and Kreitzman L. 2009. Seasons of Life - The biological rhythms that enable living things to thrive and survive. New Haven: Yale University Press.

Fromhage L, Jacobs K, and Schneider JM. 2007. Monogynous Mating Behaviour and its Ecological Basis in the Golden Orb Spider Nephila fenestrata. Ethology 113:813-820. doi:10.1111/j.14390310.2007.01383.x

Hector KL, Bishop PJ, and Nakagawa S. 2012. Consequences of compensatory growth in an amphibian. Journal of Zoology 286:93-101. 10.1111/j.1469-7998.2011.00850.x

Hector KL, and Nakagawa S. 2012. Quantitative analysis of compensatory and catch-up growth in diverse taxa. Journal of Animal Ecology 81:583-593. 10.1111/j.1365-2656.2011.01942.x

Higgins L. 1993. Constraints and Plasticity in the Development of Juvenile Nephila clavipes in Mexico. Journal of Arachnology 21:107-119.

Higgins L. 2000. The interaction of season length and development time alters size at maturity. Oecologia 122:51-59. 10.1007/pl00008835

Higgins L. 2002. Female gigantism in a New Guinea population of the spider Nephila maculata. Oikos 99:377-385.

Higgins L, Coddington J, Goodnight C, and Kuntner M. 2011. Testing ecological and developmental hypotheses of mean and variation in adult size in nephilid orb-weaving spiders. Evolutionary Ecology 25:1289-1306. 10.1007/s10682-011-9475-9

Higgins L, and Goodnight C. 2010. Nephila clavipes females have accelerating dietary requirements. Journal of Arachnology 38:150-152.

Higgins L, and Goodnight C. 2011. Developmental response to low diets by giant Nephila clavipes females (Araneae: Nephilidae). Journal of Arachnology 39:399-408.

Higgins LE. 1992. Developmental plasticity and fecundity in the orb-weaving spider Nephila clavipes. Journal of Arachnology 20:94-106.

Honek A. 1993. Intraspecific variation in body size and fecundity in insects - a general relationship. Oikos 66:483-492. 10.2307/3544943

Hornick JL, Van Eenaeme C, Gerard O, Dufrasne I, and Istasse L. 2000. Mechanisms of reduced and compensatory growth. Domestic Animal Endocrinology 19:121-132. 10.1016/s07397240(00)00072-2

Hut RA, Paolucci S, Dor R, Kyriacou CP, and Daan S. 2013. Latitudinal clines: an evolutionary view on biological rhythms. Proceedings of the Royal Society B-Biological Sciences 280. 10.1098/rspb.2013.0433

Kahn AT, Livingston JD, and Jennions MD. 2012. Do females preferentially associate with males given a better start in life? Biology Letters 8:362-364. 10.1098/rsbl.2011.1106

Kasumovic MM, and Brooks RC. 2011. It's All Who You Know: The Evolution Of Socially Cued Anticipatory Plasticity as A Mating Strategy. Quarterly Review of Biology 86:181-197.

Kasumovic MM, Bruce MJ, Herberstein ME, and Andrade MCB. 2009. Evidence for developmental plasticity in response to demographic variation in nature. Ecology 90:2287-2296. 10.1890/081540.1 
705

706

707

708

709

710

711

712

713

714

715

716

717

718

719

720

721

722

723

724

725

726

727

728

729

730

731

732

733

734

735

736

737

738

739

740

741

742

743

744

745

746

747

748

749

750

751

752

Kingsolver JG, Izem R, and Ragland GJ. 2004. Plasticity of size and growth in fluctuating thermal environments: Comparing reaction norms and performance curves. Integrative and Comparative Biology 44:450-460. 10.1093/icb/44.6.450

Kingsolver JG, and Pfennig DW. 2004. Individual-level selection as a cause of Cope's rule of phyletic size increase. Evolution 58:1608-1612.

Kleinteich A, and Schneider JM. 2010. Evidence for Rensch's rule in an orb-web spider with moderate sexual size dimorphism. Evolutionary Ecology Research 12:667-683.

Kleinteich A, and Schneider JM. 2011. Developmental strategies in an invasive spider: constraints and plasticity. Ecological Entomology 36:82-93. 10.1111/j.1365-2311.2010.01249.x

Kleinteich A, Wilder SM, and Schneider JM. 2015. Contributions of juvenile and adult diet to the lifetime reproductive success and lifespan of a spider. Oikos 124:130-138. 10.1111/oik.01421

Krause ET, and Caspers BA. 2016. Long-term consequences of early nutritional conditions on the behaviour and growth of fire salamanders. Amphibia-Reptilia 37:69-77. 10.1163/156853810003033

Kuntner M, Arnedo MA, Trontelj P, Lokovsek T, and Agnarsson I. 2013. A molecular phylogeny of nephilid spiders: Evolutionary history of a model lineage. Molecular Phylogenetics and Evolution 69:961-979. 10.1016/j.ympev.2013.06.008

Kuntner M, and Elgar MA. 2014. Evolution and maintenance of sexual size dimorphism: Aligning phylogenetic and experimental evidence. Frontiers in Ecology and Evolution 2. 10.3389/fevo.2014.00026

Kuntner M, Zhang SC, Gregoric M, and Li DQ. 2012. Nephila female gigantism attained through postmaturity molting. Journal of Arachnology 40:345-347.

Livingston JD, Kahn AT, and Jennions MD. 2014. Sex differences in compensatory and catch-up growth in the mosquitofish Gambusia holbrooki. Evolutionary Ecology 28:687-706. 10.1007/s10682-0149691-1

Mayntz D, and Toft S. 2001. Nutrient composition of the prey's diet affects growth and survivorship of a generalist predator. Oecologia 127:207-213.

Mayntz D, Toft S, and Vollrath F. 2003. Effects of prey quality and availability on the life history of a trapbuilding predator. Oikos 101:631-638.

Metcalfe NB, and Monaghan P. 2001. Compensation for a bad start: grow now, pay later? Trends in Ecology \& Evolution 16:254-260. 10.1016/s0169-5347(01)02124-3

Miyashita T. 1986. Growth, egg-production and population-density of the spider Nephila clavata in relation to food conditions in the field. Researches on Population Ecology 28:135-149. $10.1007 / \mathrm{bf02515542}$

Miyashita T. 2005. Contrasting patch residence strategy in two species of sit-and-wait foragers under the same environment: A constraint by life history? Ethology 111:159-167. 10.1111/j.14390310.2004.01048.x

Moya-Laraño J, Halaj J, and Wise DH. 2002. Climbing to reach females: Romeo should be small. Evolution 56:420-425.

Moya-Laraño J, Vinkovic D, Allard CM, and Foellmer MW. 2009. Optimal climbing speed explains the evolution of extreme sexual size dimorphism in spiders. Journal of Evolutionary Biology 22:954963. 10.1111/j.1420-9101.2009.01707.x

Nali RC, Zamudio KR, Haddad CFB, and Prado CPA. 2014. Size-Dependent Selective Mechanisms on Males and Females and the Evolution of Sexual Size Dimorphism in Frogs. American Naturalist 184:727-740. 10.1086/678455

Neumann R, and Schneider JM. 2015. Differential investment and size-related mating strategies facilitate extreme size variation in contesting male spiders. Animal Behaviour 101:107-115. 10.1016/j.anbehav.2014.12.027 
753

Neumann R, and Schneider JM. 2016. Socially cued developmental plasticity in web-building spiders. Bmc Evolutionary Biology 16. 10.1186/s12862-016-0736-7

Nylin S, and Gotthard K. 1998. Plasticity in life-history traits. Annual review of entomology 43:63-83.

Paez DJ, Fleming-Davies AE, and Dwyer G. 2015. Effects of pathogen exposure on life-history variation in the gypsymoth (Lymantria dispar). Journal of Evolutionary Biology 28:1828-1839. 10.1111/jeb.12699

Reichert S, Criscuolo F, Zahn S, Arrive M, Bize P, and Massemin S. 2015. Immediate and delayed effects of growth conditions on ageing parameters in nestling zebra finches. Journal of Experimental Biology 218:491-499. 10.1242/jeb.109942

Rittschof CC. 2010. Male density affects large-male advantage in the golden silk spider, Nephila clavipes. Behavioral Ecology 21:979-985. 10.1093/beheco/arq099

Rittschof CC. 2011. Mortality risk affects mating decisions in the spider Nephila clavipes. Behavioral Ecology 22:350-357. 10.1093/beheco/arq222

Rittschof CC, Hilber SA, Tudor MS, and St Mary CM. 2012. Modeling male reproductive strategies and optimal mate number in an orb-web spider. Behavioral Ecology 23:1-10. 10.1093/beheco/arr142

Roff DA. 1992. The evolution of life histories: theories and analysis. New York: Chapman \& Hall.

Roff DA. 2002. Life history evolution.

Schaefer D, and Uhl G. 2003. Male competition over access to females in a spider with last-male sperm precedence. Ethology 109:385-400.

Schneider JM, and Andrade MCB. 2011. Mating behaviour and sexual selection. In: Herberstein ME, ed. Spider Behaviour: Cambridge University Press, 215-255.

Schneider JM, and Elgar MA. 2005. The combined effects of pre- and post-insemination sexual selection on extreme variation in male body size. Evolutionary Ecology 19:419-433. 10.1007/s10682-0058310-6

Schneider JM, Herberstein ME, Bruce MJ, Kasumovic MM, Thomas ML, and Elgar MA. 2008. Male copulation frequency, sperm competition and genital damage in the golden orb-web spider (Nephila plumipes). Australian Journal of Zoology 56:233-238. 10.1071/zo08041

Schneider JM, Lucass C, Brandler W, and Fromhage L. 2011. Spider Males Adjust Mate Choice but Not Sperm Allocation to Cues of a Rival. Ethology 117:970-978. 10.1111/j.1439-0310.2011.01960.x

Schneider JM, and Michalik P. 2011. One-shot genitalia are not an evolutionary dead end - Regained male polygamy in a sperm limited spider species. Bmc Evolutionary Biology.

Smith MD, and Brockmann HJ. 2014. The evolution and maintenance of sexual size dimorphism in horseshoe crabs: an evaluation of six functional hypotheses. Animal Behaviour 96:127-139. 10.1016/j.anbehav.2014.08.005

Stearns SC. 1992. The evolution of life histories. Oxford: Oxford University Press.

Stillwell RC, and Davidowitz G. 2010. Sex differences in phenotypic plasticity of a mechanism that controls body size: implications for sexual size dimorphism. Proceedings of the Royal Society BBiological Sciences 277:3819-3826. 10.1098/rspb.2010.0895

Tawes BR, and Kelly CD. 2017. Sex-specific catch-up growth in the Texas field cricket, Gryllus texensis. Biological Journal of the Linnean Society 120:90-101.

Uhl G, Schmitt S, Schafer MA, and Blanckenhorn W. 2004. Food and sex-specific growth strategies in a spider. Evolutionary Ecology Research 6:523-540.

Vergauwen J, Heylen D, Eens M, and Muller W. 2011. Negative Effects of Yolk Testosterone and Ticks on Growth in Canaries. Journal of Experimental Zoology Part a-Ecological Genetics and Physiology 315A:553-561. 10.1002/jez.704

Walzer A, Lepp N, and Schausberger P. 2015. Compensatory growth following transient intraguild predation risk in predatory mites. Oikos 124:603-609. 10.1111/oik.01687

West-Eberhard MJ. 2003. Developmental plasticity and evolution: Oxford University Press. 
801 Wilson PN, and Osbourn DF. 1960. Compensatory growth after undernutrition in mammals and birds.

802 Biological Reviews of the Cambridge Philosophical Society 35:324-363. 10.1111/j.1469-

$803 \quad$ 185X.1960.tb01466.x

804 


\section{Table $\mathbf{1}$ (on next page)}

Effects of interactions between the variables early treatment, family lineage, and sex on body mass at completion of the early experiment.

Results derive from a linear mixed model including the variable Start date (the time of allocating hatchlings to individual treatments) as a random effect to account for a potential influence of photoperiod on development. Body mass was log-transformed. Significant $P$ values are shown in bold. 


\begin{tabular}{llr}
$\begin{array}{l}\text { Explanatory } \\
\text { variable }\end{array}$ & $\begin{array}{l}\text { Body mass } \\
\text { at completion of } \\
\text { the early experiment }\end{array}$ \\
& $F$ & $P$ \\
& & \\
Early treatment & 1822.1 & $<0.0001$ \\
Family lineage & 6.5 & $<0.0001$ \\
Sex & 427.6 & $<0.0001$ \\
$\begin{array}{l}\text { Early treatment } \\
\text { * Family lineage } \\
\text { Early treatment } \\
* \text { Sex }\end{array}$ & 8.6 & $<0.0001$ \\
\hline
\end{tabular}




\section{Table 2 (on next page)}

Pre-maturation mortality compared between feeding treatments.

Treatment pairs were compared using G-tests. Significant $P$-values are shown in bold. 
1

2

\begin{tabular}{llll}
\hline $\begin{array}{l}\text { Treatment pair } \\
\text { (\% mortality) }\end{array}$ & $\chi^{2}$ & $P$ & $N$ \\
High-Low (21\%) - Low-Low (24.7\%) & 1.044 & 0.307 & 569 \\
High-Low (21\%) - High-High (9.3\%) & 15.393 & $<0.0001$ & 564 \\
High-High (9.3\%) - Low-High (13.9\%) & 2.816 & 0.093 & 545 \\
High-High (9.3\%) - Low-Low (24.7\%) & 24.156 & $<0.0001$ & 563 \\
Low-High (13.9\%)- Low-Low (24.7\%) & 10.264 & $\mathbf{0 . 0 0 1}$ & 550 \\
High-Low (21\%)- Low-High (13.9\%) & 4.886 & $\mathbf{0 . 0 2 7}$ & 551 \\
\hline
\end{tabular}

3

4 


\section{Table 3(on next page)}

Total developmental durations and adult size compared between feeding treatments.

Treatments were compared with Steel-Dwass pairwise tests (excluding treatment pair HighHigh - Low-High subject to predefined analysis of catch-up growth; see results). Significant $P$-values are shown in bold. 


\begin{tabular}{|c|c|c|c|c|c|c|c|c|}
\hline \multirow{3}{*}{$\begin{array}{l}\text { Treatment } \\
\text { pair }\end{array}$} & \multicolumn{4}{|c|}{ Males } & \multicolumn{4}{|c|}{ Females } \\
\hline & \multicolumn{2}{|c|}{$\begin{array}{l}\text { Total duration } \\
\text { of development }\end{array}$} & \multicolumn{2}{|c|}{$\begin{array}{l}\text { Adult body } \\
\text { size }\end{array}$} & \multicolumn{2}{|c|}{$\begin{array}{l}\text { Total duration } \\
\text { of development }\end{array}$} & \multicolumn{2}{|c|}{$\begin{array}{l}\text { Adult body } \\
\text { size }\end{array}$} \\
\hline & Z & $P(N)$ & Z & $P(N)$ & $\chi^{2}$ & $P(N)$ & Z & $P(N)$ \\
\hline $\begin{array}{l}\text { High-High } \\
\text { - Low-Low }\end{array}$ & 10.42 & $\begin{array}{l}<0.0001 \\
(184)\end{array}$ & 9.06 & $\begin{array}{l}<0.0001 \\
(181)\end{array}$ & 284.84 & $\begin{array}{l}<0.0001 \\
(283)\end{array}$ & 13.55 & $\begin{array}{l}<0.0001 \\
(275)\end{array}$ \\
\hline $\begin{array}{l}\text { High-High } \\
\text { - High-Low }\end{array}$ & 7.17 & $\begin{array}{l}<0.0001 \\
(182)\end{array}$ & 6.86 & $\begin{array}{l}<0.0001 \\
(179)\end{array}$ & 226.58 & $\begin{array}{l}<0.0001 \\
(296)\end{array}$ & 13.74 & $\begin{array}{l}<0.0001 \\
(285)\end{array}$ \\
\hline $\begin{array}{l}\text { Low-Low } \\
\text { - High-Low }\end{array}$ & 7.24 & $\begin{array}{l}<0.0001 \\
(172)\end{array}$ & 5.32 & $\begin{array}{l}0.0008 \\
(168)\end{array}$ & 4.67 & $\begin{array}{l}0.2 \\
(267)\end{array}$ & 2.11 & $\begin{array}{l}0.151 \\
(262)\end{array}$ \\
\hline $\begin{array}{l}\text { Low-Low } \\
\text { - Low-High }\end{array}$ & 6.47 & $\begin{array}{l}<0.0001 \\
(180)\end{array}$ & 4.92 & $\begin{array}{l}<0.0001 \\
(173)\end{array}$ & 108.55 & $\begin{array}{l}<0.0001 \\
(263)\end{array}$ & 12.26 & $\begin{array}{l}<0.0001 \\
(260)\end{array}$ \\
\hline $\begin{array}{l}\text { High-Low } \\
\text { - Low-High }\end{array}$ & 0.15 & $\begin{array}{l}0.999 \\
(178)\end{array}$ & 0.95 & $\begin{array}{l}0.776 \\
(171)\end{array}$ & 71.9 & $\begin{array}{l}<0.0001 \\
(276)\end{array}$ & 12.14 & $\begin{array}{l}<0.0001 \\
(270)\end{array}$ \\
\hline
\end{tabular}




\section{Table 4 (on next page)}

Effects of interactions between treatment, family lineage, and sex on total duration of development and adult size.

Results derive from linear mixed models including the variable Start date (the time of allocation of hatchlings to individual treatments) as a random effect to account for a potential influence of photoperiod on development. Developmental durations were log-transformed. Significant $P$-values are shown in bold. 


\begin{tabular}{lllll}
\hline $\begin{array}{l}\text { Explanatory } \\
\text { variable }\end{array}$ & \multicolumn{2}{l}{$\begin{array}{l}\text { Total duration } \\
\text { of development }\end{array}$} & \multicolumn{2}{l}{ Adult body size } \\
& $F$ & $P$ & $F$ & $P$ \\
Treatment & 339.96 & $<0.0001$ & 343.43 & $\mathbf{0 . 0 0 7}$ \\
Family lineage & 10.3 & $<0.0001$ & 2.31 & $\mathbf{0 . 0 3 3}$ \\
Sex & 821.48 & $<0.0001$ & 7219.27 & $<0.0001$ \\
$\begin{array}{l}\text { Treatment } \\
\text { * Family lineage }\end{array}$ & 3.14 & $<0.0001$ & 1.94 & $\mathbf{0 . 0 0 7}$ \\
$\begin{array}{l}\text { Treatment } \\
\text { * Sex }\end{array}$ & 27.54 & $<0.0001$ & 115.98 & $<0.0001$ \\
\hline
\end{tabular}




\section{Figure 1}

Adaptive catch-up growth in (A) male and (B) female Nephila senegalensis.

Symbols indicate median values for body mass at the beginning of the Late-experiment development and body mass at sexual maturation in treatments High-High (blue squares) and Low-High (red triangles). Late-experiment development in the High-High treatment followed four weeks of early high feeding conditions. Late-experiment development in the Low-High treatment followed four weeks of early low feeding conditions. Body mass is given as a proxy of body size (*, indicates significant differences).
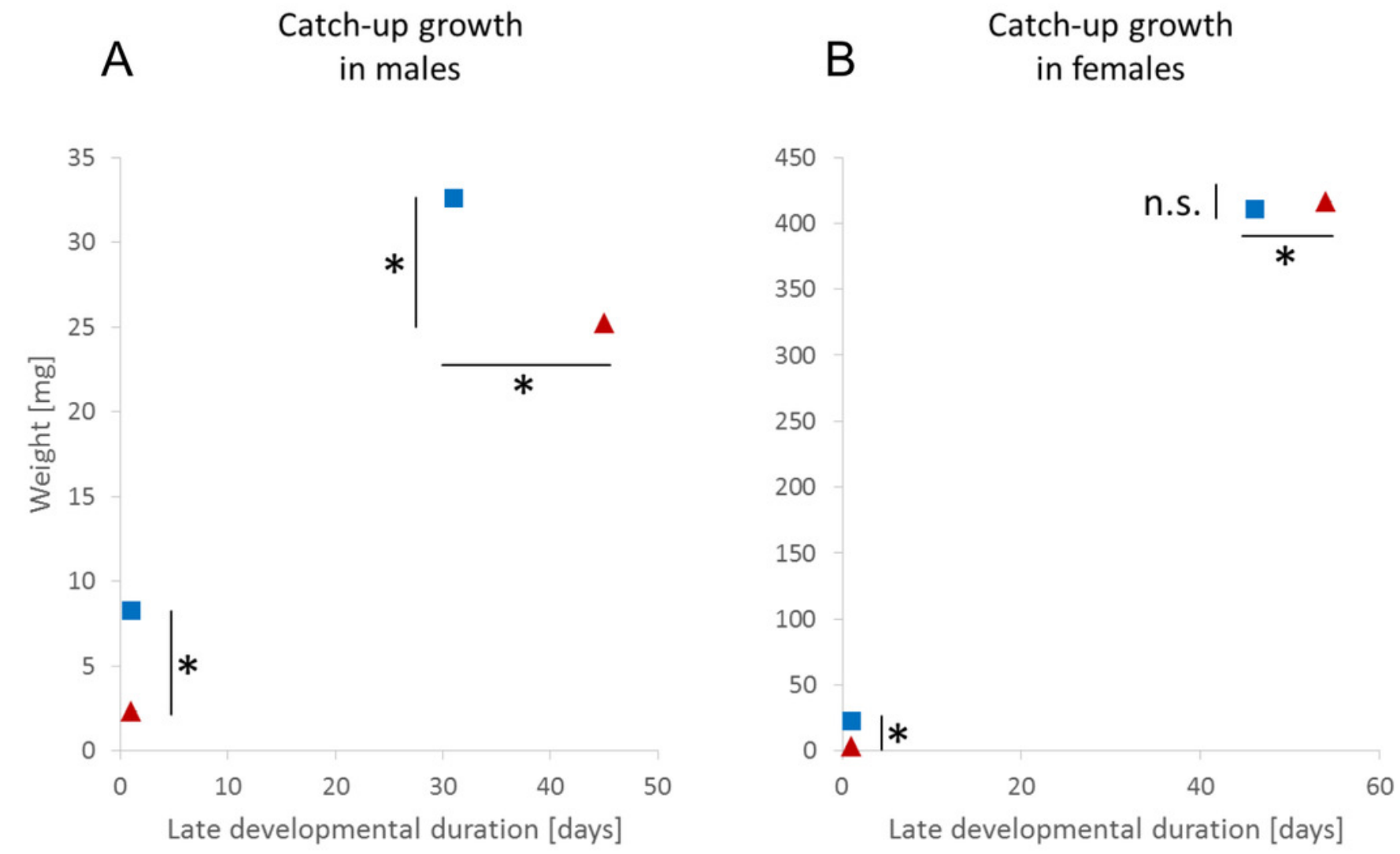
Figure 2

Effects of feeding treatments on the duration of development and adult size in Nephila senegalensis.

Top row $(A, B)$ : Males. Bottom row $(C, D)$ : Females. Treatments were High-High $(H-H)$, LowLow (L-L), High-Low (H-L), and Low-High (L-H).

A

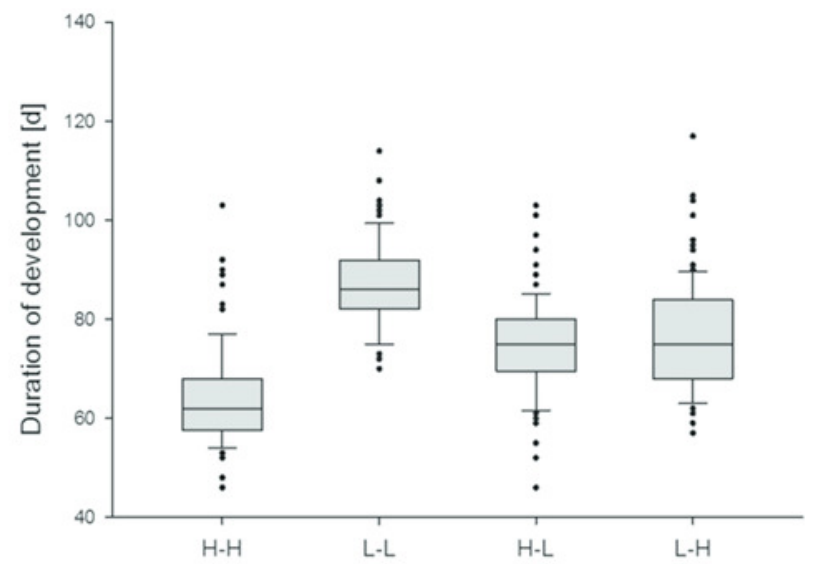

C

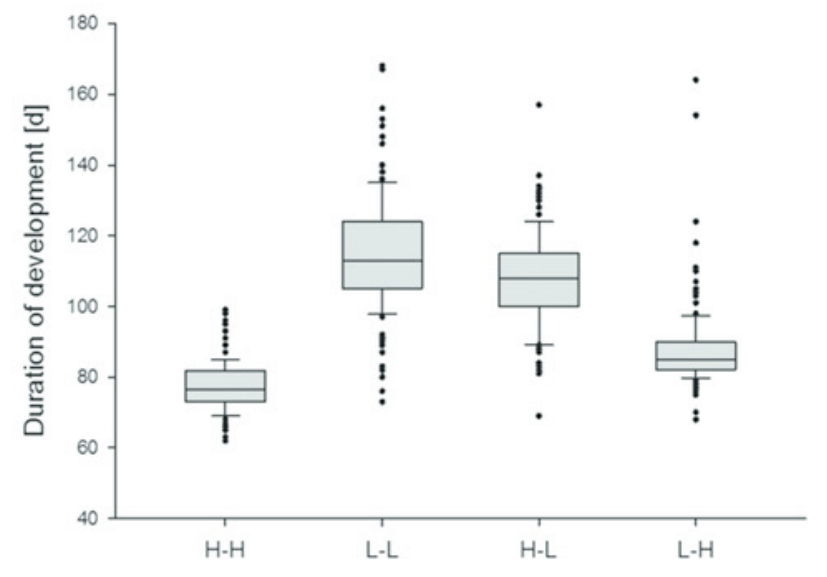

Feeding treatment
B

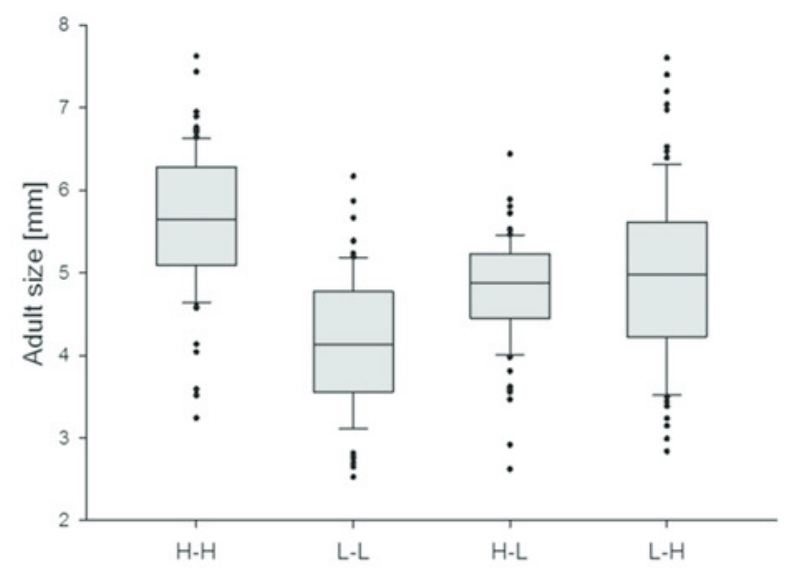

D

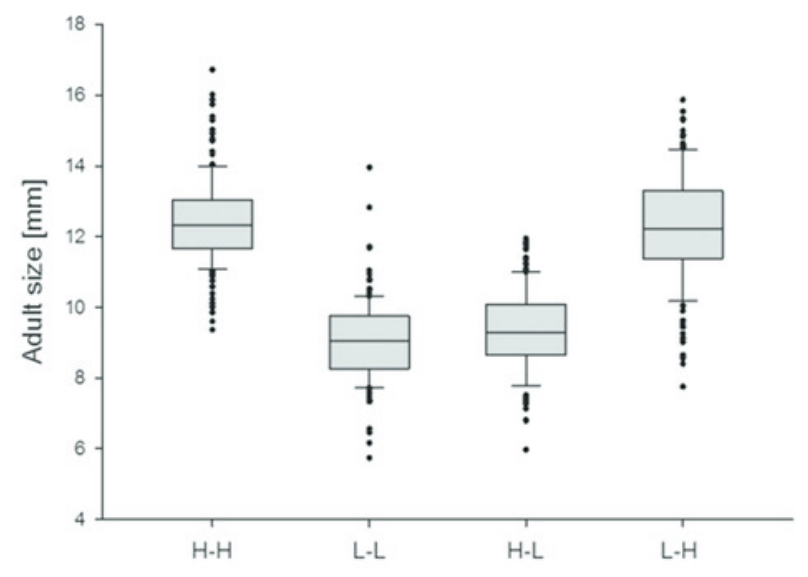

Feeding treatment 
Figure 3

Effects of feeding treatments on life-time fecundity (LTF) in Nephila senegalensis.

The interaction between feeding treatment and the number of clutches produced explained life-time fecundity in a linear model (adjusted $R^{2}=0.83$ ). Treatments were High-High (blue), Low-High (red), and Low-Low (green). Shaded areas indicate $95 \%$ confidence intervals.

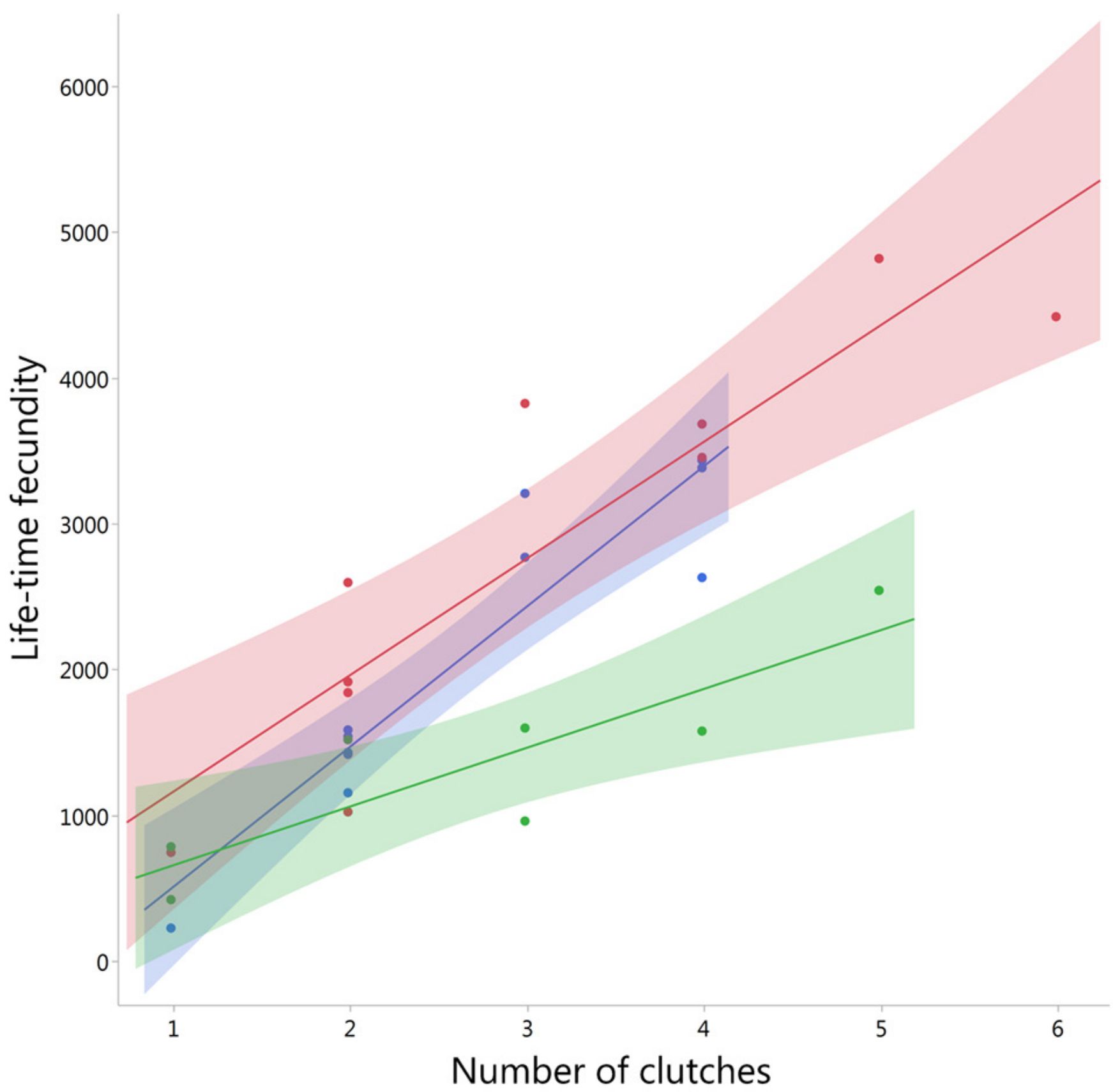

